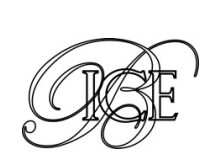

Enrique Feás Costilla*

Jesús Felipe**

\title{
FILIPINAS: CRECIMIENTO Y CAMBIO ESTRUCTURAL
}

Filipinas es una democracia de cien millones de habitantes, en su gran mayoría jóvenes y angloparlantes, que goza de una situación macroeconómica relativamente saneada y un crecimiento prometedor. No obstante, se enfrenta a los retos de desarrollar sus infraestructuras, combatir la pobreza y mantener un crecimiento sostenido a largo plazo de su renta por habitante. En este artículo se describirá la situación económica de Filipinas, sus fortalezas, sus debilidades y sus riesgos, para analizar más adelante si se encuentra en la denominada «trampa de la renta media» y qué factores podrían favorecer el cambio estructural necesario para convertir a Filipinas, en un futuro no lejano, en una economía de renta alta.

Palabras clave: Filipinas, desarrollo, trampa de la renta media, cambio estructural.

Clasificación JEL: F63, H54, L16, O11, O14.

\section{Introducción}

Filipinas es uno de los países del continente asiático que ha experimentado una mejor evolución económica en la última década. Desde la crisis asiática de 1998 ha venido creciendo de forma sostenida a tasas superiores a la media mundial y a la de la ASEAN-51. Esto es particularmente evidente en el período 2010-2015, en el que Filipinas creció a una media del 6,2 por 100 , frente al 5,4 por 100 de la ASEAN-5 y al 3,7 por 100 mundial. Gran parte del éxito económico de los últimos años cabe atribuirlo a una prudente gestión macroeconómica y financiera que han convertido a Filipinas en uno de los países mejor preparados para afrontar una crisis financiera.

\footnotetext{
* Técnico Comercial y Economista del Estado. Consejero Económico y Comercial en la Embajada de España en Filipinas.

** Advisor, Economic Research and Regional Cooperation Department, Asian Development Bank. Las opiniones del autor no reflejan necesariamente las de la institución, las de los miembros de su Consejo, o las de los países a los que estos representan.

Versión de abril de 2016.

1 ASEAN-5: Filipinas, Indonesia, Malasia, Tailandia y Vietnam.
}

Un análisis más profundo de la situación económica de Filipinas requiere, no obstante, el estudio de los factores no sólo coyunturales, sino también estructurales, en los que hay luces y sombras.

A lo largo de este artículo analizaremos, en primer lugar, la evolución reciente de la situación macroeconómica de Filipinas, para después profundizar en sus problemas estructurales de desempleo y pobreza, y sus vínculos con la escasez de inversión (sobre todo pública) y la deficiencia de infraestructuras. Más adelante comprobaremos si Filipinas se encuentra en la denominada «trampa de la renta media», y concluiremos analizando la necesidad de un cambio estructural en Filipinas y sus factores impulsores.

\section{El marco macroeconómico de Filipinas}

Filipinas ha venido creciendo en los últimos diez años a una envidiable tasa media superior al 5,5 por 100, y en los últimos cinco al 6,2 por 100 . Tan sólo ha vivido una fugaz desaceleración en $\triangleright$ 


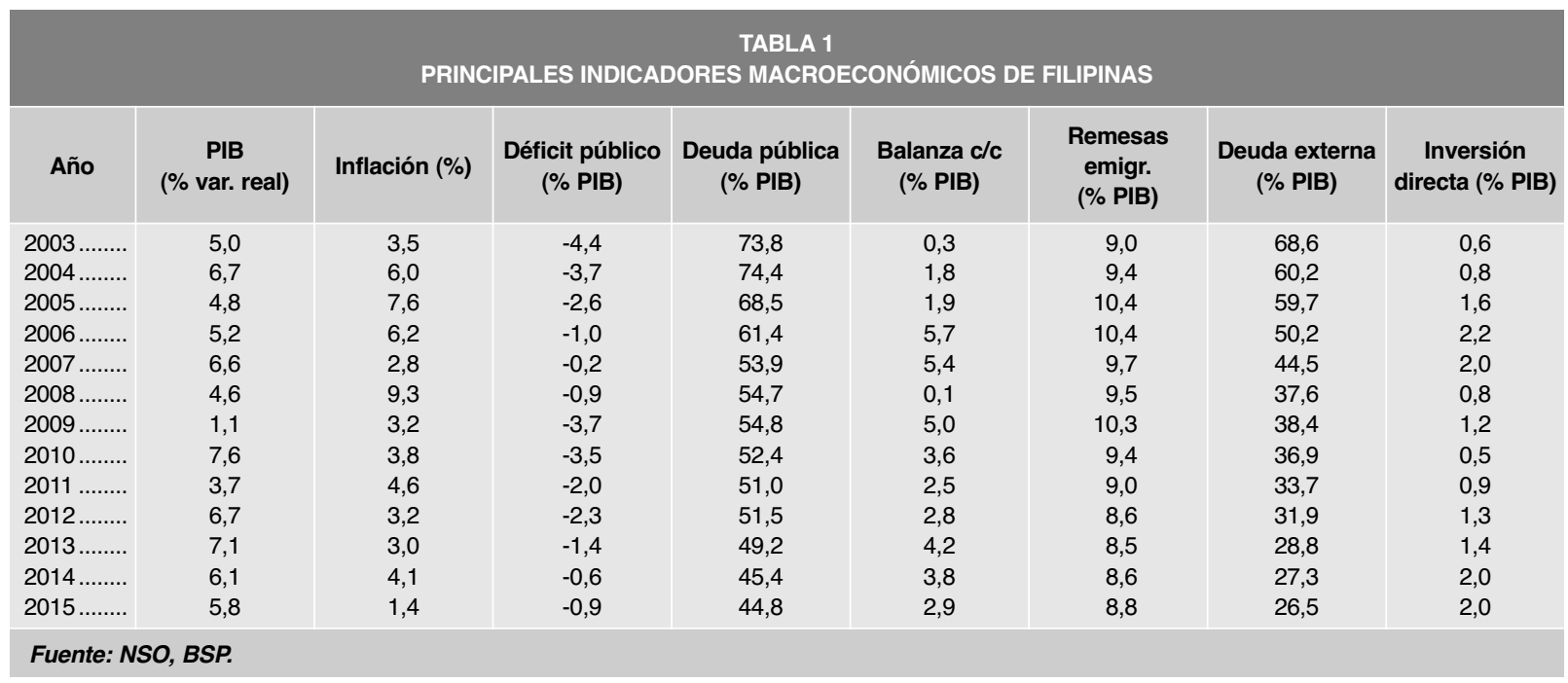

2011, e incluso el menor crecimiento de 2015 del 5,8 por 100 sigue siendo de los más elevados de la región.

Ese elevado crecimiento se explica, por el lado del gasto, por la demanda interna, gracias al pujante consumo e inversión privados. La inversión privada, a su vez, viene en gran medida impulsada por los bienes de equipo y por la construcción, en proporciones que alejan, por el momento, el fantasma de una posible burbuja inmobiliaria que pareció asomar en 2013. El gasto público, sin embargo, se mantiene en niveles relativamente bajos.

La demanda externa, por el contrario, supone en los últimos años un auténtico freno al crecimiento, con aportaciones al PIB escasas o negativas (de casi cuatro puntos en 2015) y que podrían llegar a comprometer el crecimiento futuro.

Por el lado de la oferta, el crecimiento en los últimos años viene explicado principalmente por el dinamismo de los servicios (con crecimientos entre el 7 por 100 y el 9 por 100), gracias al comercio y al espectacular desarrollo en el país de los denominados centros de Subcontratación de Procesos de Negocios (Business Process Outsourcing o BPO en sus siglas en inglés), que han convertido a Filipinas en el líder mundial en centros de voz (call centers), sector que sin embargo no presenta altas cifras de ingresos por trabajador. La industria crece a un ritmo ligeramente inferior, mientras que la agricultura, que absorbe aún a un 31 por 100 de la población activa, apenas crece al 2 por 100 y con tasas de productividad muy bajas.

La inflación se mantiene estable desde 2009 entre el 3 y el 4 por 100 (con la única excepción del repunte de 4,6 por 100 en 2011), y en 2015 fue de apenas un 1,4 por 100. El déficit fiscal es reducido, sistemáticamente inferior al 3 por 100 del PIB desde 2004, y la deuda pública del Gobierno central es inferior al 50 por 100 del PIB desde el año 2003.

La balanza de pagos, por su parte, presenta un continuado superávit por cuenta corriente desde 2003, que hay que atribuir no tanto a la balanza de bienes y servicios (que es deficitaria en cada una de sus subbalanzas ${ }^{2}$ ) sino a la extraordinariamente positiva balanza de transferencias, impulsada por los numerosos trabajadores filipinos en el exterior que envían de vuelta anualmente entre un 8 y un 9 por 100 del PIB en forma de remesas (25.800 millones de dólares en 2015). La deuda externa pasó del 68 por 100 del PIB en 2003 al 26,5 por 100 en 2015 (con una reducción de casi 42 puntos en 12 años). Las reservas internacionales, que apenas cubrían el 30 por 100 de la deuda externa en 2003, podrían saldarla en su totalidad con sus niveles de finales de 2015 (80.700 millones de dólares).

\footnotetext{
2 Llama la atención el creciente déficit de la balanza de turismo desde 2008 (en 2014 alcanzó los 6.380 millones de dólares), especialmente porque se considera habitualmente que el turismo es uno de los sectores de mayor potencial de Filipinas, cuando a día de hoy es un creciente motivo de salida neta de divisas.
} 


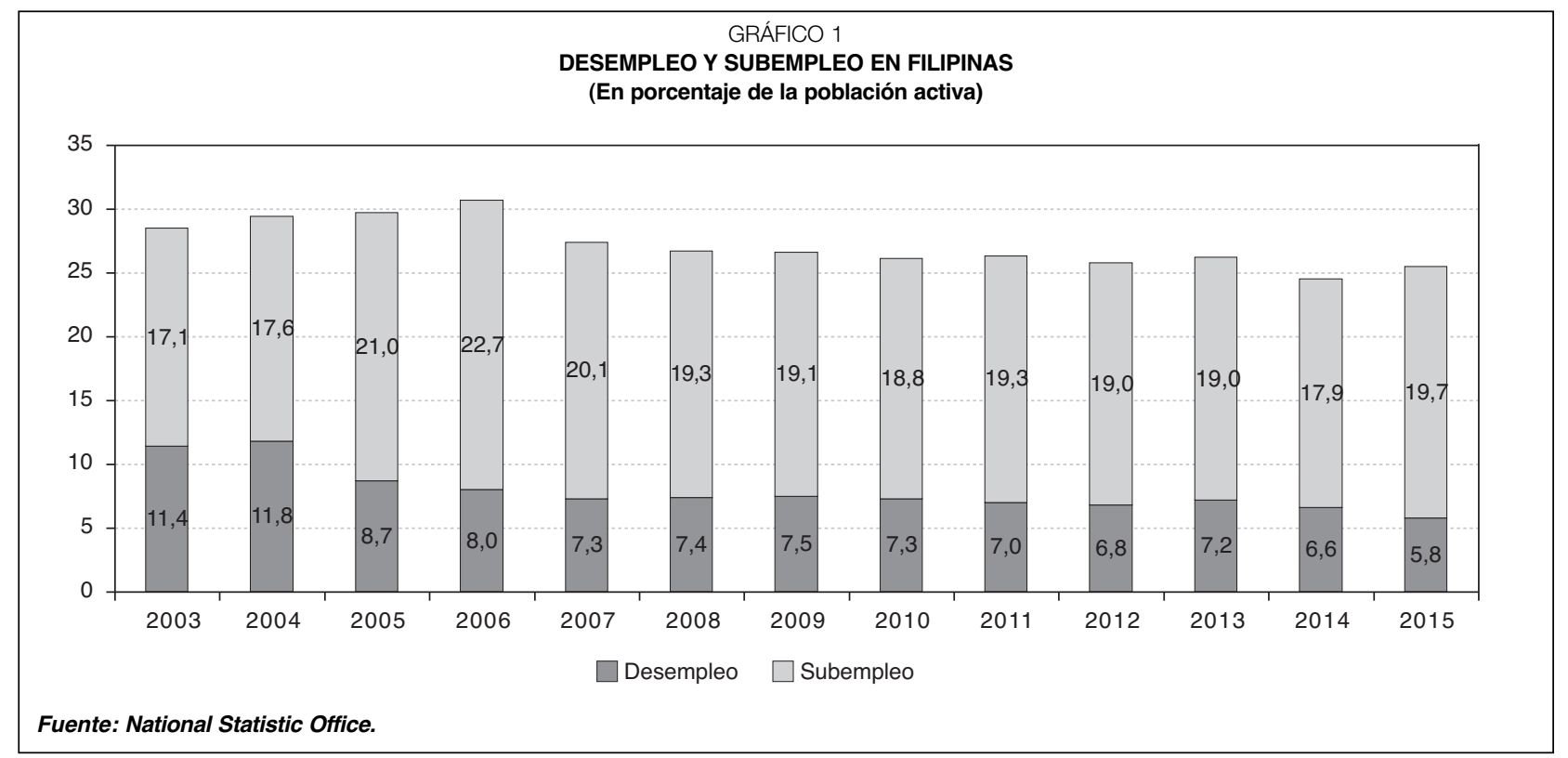

No es de extrañar, por tanto, que las agencias de calificación hayan revisado al alza el rating crediticio de Filipinas, otorgándole en 2013 el grado de inversión. Así, a comienzos de 2016 Filipinas tenía una calificación BBB estable de S\&P, Baa2 estable de Moody's y BBB- positiva de Fitch, y era calificado por The Economist como uno de los países emergentes más resistentes del mundo ante una potencial caída repentina de los flujos de entrada de capitales (Capital Freeze Index).

\section{Desempleo y pobreza. El problema de las infraestructuras}

Este sólido panorama financiero contrasta con la situación del sector real, donde el equilibrio interno se rompe por la parte del empleo: así, y aunque entre 2003 y 2015 la cifra oficial de desempleo ha pasado de un 11,4 a un 5,8 por 100 de la población activa, el subempleo (en cifras oficiales y expresado asimismo en porcentaje de la población activa) permanece en niveles cercanos al 20 por 100, manteniendo una presión a la baja sobre los salarios.

Ello explica por qué el fuerte crecimiento de Filipinas no ha permitido hasta el momento beneficiar a las capas más desfavorecidas de la población, así, si en 2003 el porcentaje de la población filipina por debajo del umbral de pobreza era del 25 por 100, en 2014 era del 25,8 , lo que implica que, pese al fuerte crecimiento, uno de cada cuatro filipinos sigue por debajo de dicho umbral y que en 2014 había cinco millones más de pobres que en 2003.

Es evidente, por tanto, que el crecimiento de Filipinas no resulta suficiente para generar empleo de calidad y salarios dignos: con una población de 100 millones de habitantes y que aumenta a una tasa media del 2 por 100, Filipinas requiere alcanzar tasas de crecimiento muy superiores para poder asegurar una reducción efectiva de la pobreza.

Sin duda, una de las causas de esa dificultad para incrementar y permeabilizar ese crecimiento se encuentra en las deficientes infraestructuras del país, que encarecen el coste de la actividad económica e impiden aprovechar el potencial de otros sectores.

Filipinas, aun siendo uno de los países del Sudeste Asiático que más crece, es uno de los que peor nivel de infraestructuras presenta. Así, si el Banco Mundial calculaba en 2005 las necesidades de inversión en infraestructuras en los países en desarrollo del Sudeste Asiático en un 5 por 100 del PIB, Filipinas no ha alcanzado esa cifra en ningún año desde entonces (salvo quizás 2015). En el Global Competitive Index $(\mathrm{GCl})$ del World Economic $\triangleright$ 
Forum Filipinas ocupaba en 2015-2016 el puesto 47 (de 140) en competitividad global, pero en infraestructuras ocupaba el puesto 90 .

La evidencia empírica confirma los importantes efectos de las infraestructuras sobre el crecimiento y el desarrollo. Así, Calderón (2004) estima una elasticidad crecimiento-gasto en infraestructuras en torno al 0,1 ; lo que implicaría que por cada incremento del 10 por 100 en el gasto en infraestructuras aumentaría el crecimiento del PIB a largo plazo en un 1 por 100. Seneviratne y Sun (2013), por su parte, encuentran que la calidad y la cantidad de infraestructuras mejoran la distribución de la renta, al aumentar la productividad y el crecimiento y gracias a los efectos de estos sobre la reducción de la pobreza y el crecimiento inclusivo. Estos resultados tienen sentido en Filipinas, donde existe una elevada concentración y centralización de la producción, de modo que en la capital y sus alrededores (las dos regiones de NCR -National Capital Region- o Metro Manila y Calabarzon), que apenas suponen el 5,6 por 100 del territorio, se concentra el 26 por 100 de la población y el 54 por 100 del PIB.

\section{La financiación de infraestructuras en Filipinas}

El Gobierno filipino, consciente de la escasa cantidad y calidad de las infraestructuras del país y de su importante efecto sobre la productividad y el crecimiento, decidió en 2010 impulsar el desarrollo de las infraestructuras, basándose principalmente en un ambicioso programa de partenariado público-privado (PPP) que poco a poco alcanzó un buen ritmo. Entre 2010 y 2016 se aprobaron 12 proyectos por valor de 4.430 millones de dólares, la mayoría en el sector de transportes (carretera, ferrocarril y aeropuertos), y a comienzos de 2016 había en licitación otros 16 por valor de 13.833 millones de dólares.

Pese a este esfuerzo, la inversión sigue siendo insuficiente. Si consideramos el gasto total en

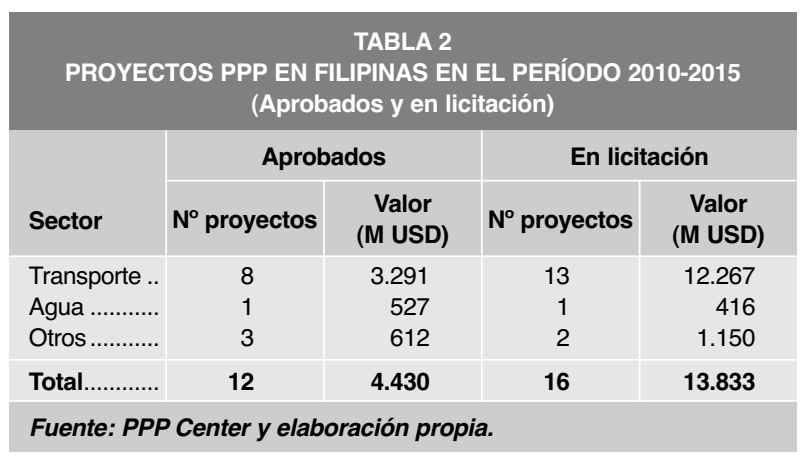

infraestructuras en el período 2010 y 2015 se observa (Tabla 3) que los proyectos PPP apenas suponen una media del 0,3 por 100 del PIB en este período, que se suman a una inversión pública media del 2,6 por 100 del PIB, lo que arroja un total de gasto medio en infraestructuras para el período del 2,9 por 100, muy por debajo del 5 por 100 recomendado por el Banco Mundial (que equivaldría a unos 14.600 millones de dólares anuales) ${ }^{3}$.

Esa inversión adicional en infraestructuras no va a venir del exterior: la inversión directa extranjera, que por desgracia sigue siendo percibida en Filipinas como una mera fuente de financiación, cuando en realidad lo es sobre todo de competencia, creación de empleo y crecimiento, permanece estancada desde hace años en el entorno de los 3.0004.000 millones de dólares, cifra ridícula en términos absolutos y en términos comparativos con los países de su entorno. Las causas hay que buscarlas en las fuertes restricciones legales y constitucionales a la inversión extranjera, la inseguridad jurídica y la presión de los grandes grupos locales. A corto y medio plazo, sin embargo, será imprescindible que los inversores extranjeros adopten un papel más activo en el desarrollo de las infraestructuras filipinas, ya que los grandes grupos locales, pese a su fortaleza y solidez financiera, no tienen ni el tamaño suficiente para competir en el nuevo marco de la ASEAN ni la capacidad de asumir riesgos $D$

\footnotetext{
3 Bhattacharyay (2010) hace un cálculo más preciso de las necesidades de infraestructuras de Filipinas, que estima en 127.122 millones de dólares para la década de 2010-2020. Sobre esta base, los datos muestran que en el período 2010-2015 tan sólo se habría cubierto un 35,7 por 100 de esa cifra. Para poder cubrir este gap de casi 82.000 millones en los años que restan hasta 2020 se requeriría una inversión mínima anual de 20.430 millones de dólares, equivalente a un 7 por 100 del PIB de 2015.
} 


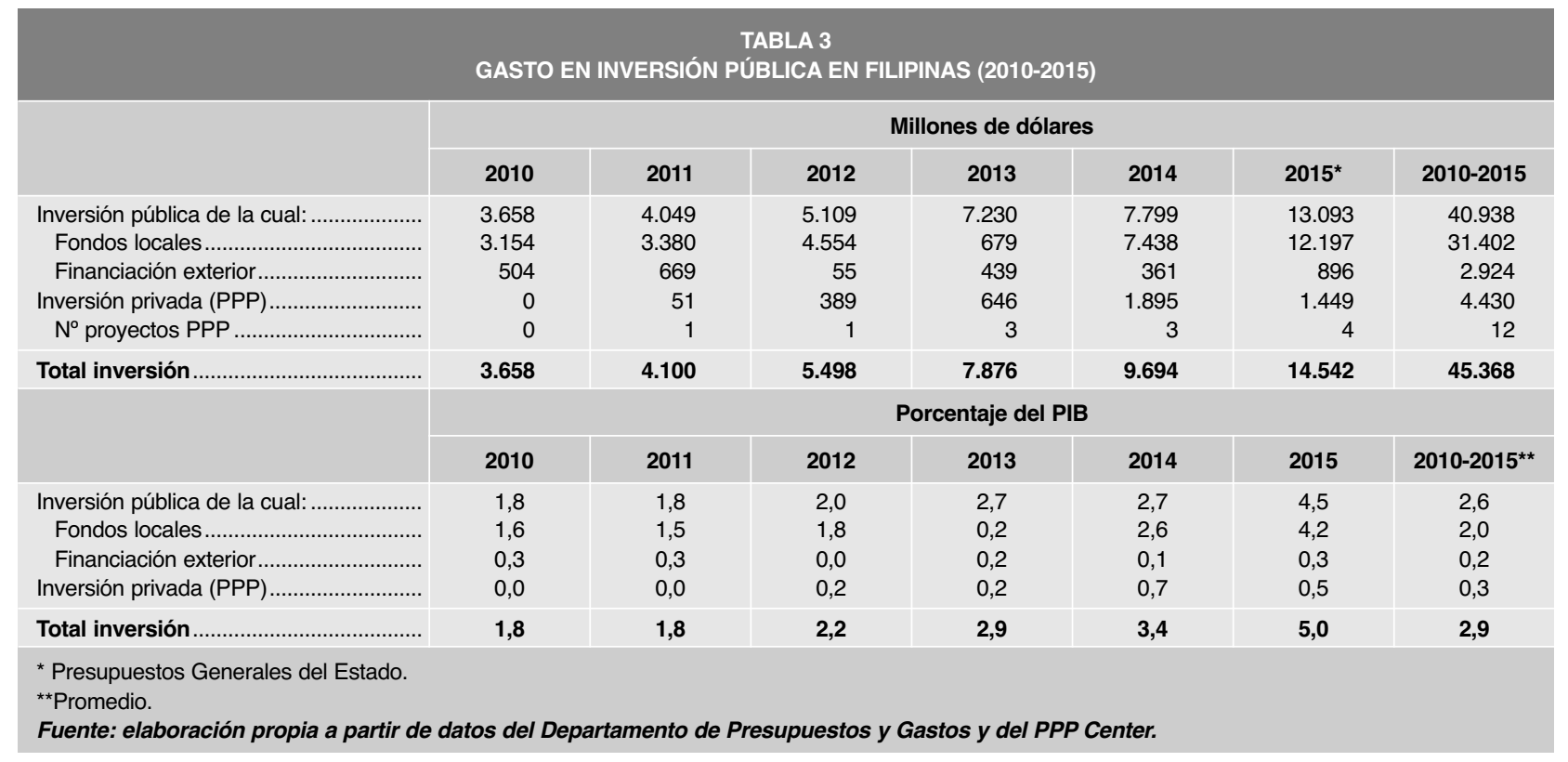

crecientes fuera de balance como líderes de los grandes consorcios de desarrollo de infraestructuras en PPP.

En cualquier caso, parece claro, por tanto, que se han depositado demasiadas expectativas en la estrategia de PPP, que a fin de cuentas no es más que una forma más de financiar infraestructuras, pero no la única ni necesariamente la prioritaria. De hecho, como señala el Banco Mundial (2012), la experiencia desde los años noventa demuestra que, aunque el sector privado se ha convertido en una fuente importante de financiación de infraestructuras, no puede sustituir al sector público, que sigue siendo un actor fundamental.

Ese actor, por desgracia, ha permanecido pasivo en Filipinas. Así, en los últimos años se puede decir que el crecimiento en Filipinas ha estado impulsado por el sector privado, en especial por el lado del consumo privado y por el de una inversión privada dinámica, pero insuficiente, para alcanzar los niveles de formación bruta de capital necesarios para que el país se desarrolle. La inversión del sector público, por el contrario, ha sido demasiado tímida.

Lo cierto, sin embargo, es que la inversión pública tendría aún bastante margen: la Tabla 4 muestra las relaciones de ahorro e inversión de los sectores privado, público y exterior en Filipinas y sus principales competidores de la ASEAN-5. Como se puede observar, la inversión total de Filipinas en porcentaje del PIB (20,9 por 100 en 2014) es en torno a cinco puntos inferior a la media de los países de la región. La causa de este bajo nivel de inversión viene explicada por la escasez de inversión pública que se esconde tras las bajas cifras de gasto público total (entre 4 y 9 puntos inferior al de sus competidores $)^{4}$.

Por tanto, hasta ahora la baja inversión pública ha dificultado la mejora de las deficientes infraestructuras de Filipinas. Sin embargo, existe margen más que suficiente para que el sector público adopte una política de inversión mucho más activa y que complemente de forma adecuada a la privada y a los proyectos PPP.

A menudo se menciona (FMl, 2015) que uno de los problemas para asumir un mayor nivel de gasto público en infraestructuras se debe al bajo nivel estructural de sus ingresos públicos, estancados desde hace más de diez años por debajo del 20 por 100 del PIB y constreñidos por una elevada elusión fiscal (ya que los tipos impositivos sobre la renta y sobre el consumo son de los más altos de la región). $D$

\footnotetext{
4 Empleando la identidad entre capacidades de financiación del sector privado (S-I), sector público (T-G) y sector exterior (X-M), de modo que (S-I) + $+(T-G)=(X-M)$, se observa que Filipinas es el único que presenta una moderada capacidad de financiación en los tres ámbitos. Como contraste, Vietnam (y en menor medida, Malasia) presentarían una elevada capacidad de financiación del sector privado y una elevada necesidad de financiación del sector público.
} 


\begin{tabular}{|c|c|c|c|c|c|}
\hline \multicolumn{6}{|c|}{$\begin{array}{c}\text { TABLA } 4 \\
\text { FINANCIACIÓN DE LA INVERSIÓN EN LA ASEAN-5 (2014) } \\
\text { (En porcentaje del PIB) }\end{array}$} \\
\hline & Indonesia & Malasia & Filipinas & Tailandia & Vietnam \\
\hline 1. Ahorro nacional bruto & 31,7 & 29,3 & 25,4 & 27,4 & 30,5 \\
\hline 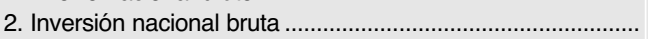 & 34,7 & 25,0 & 20,9 & 24,1 & 25,6 \\
\hline 3. Ingresos públicos & 16,7 & 23,3 & 19,3 & 21,3 & 21,9 \\
\hline 4. Gasto público & 18,8 & 26,9 & 18,4 & 22,2 & 28,0 \\
\hline 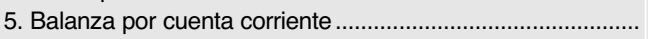 & $-3,0$ & 4,3 & 4,4 & 3,3 & 4,9 \\
\hline 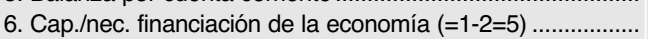 & $-3,0$ & 4,3 & 4,4 & 3,3 & 4,9 \\
\hline 7. Cap./nec. financiación del sector público $(=3-4)$.................. & $-2,1$ & $-3,6$ & 0,9 & $-0,8$ & $-6,1$ \\
\hline \multicolumn{6}{|l|}{ Pro memoria: } \\
\hline 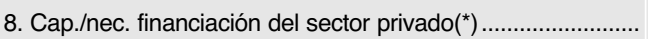 & $-0,9$ & 7,9 & 3,6 & 4,2 & 11,1 \\
\hline 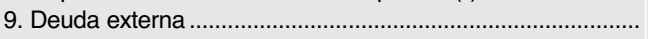 & 33,1 & 63,2 & 27,3 & 34,8 & n.d. \\
\hline
\end{tabular}

Sin embargo, en la misma Tabla 4 se observa que la escasez de ingresos públicos tan sólo explica parcialmente la diferencia de inversión con sus principales vecinos (la diferencia con Tailandia y Vietnam es menor de cuatro puntos, y negativa en el caso de Indonesia, que recauda aún menos que Filipinas). La diferencia de niveles de inversión en Filipinas cabe atribuirla más bien a un sector público que gasta entre 4 y 9 puntos menos de PIB.

No resulta muy comprensible que Filipinas, con un déficit público del 1,4 por 100, una deuda pública del 36 por $100^{5}$ y una deuda externa inferior al 28 por 100 del PIB, no aproveche su margen para asumir un mayor gasto público en infraestructuras de elevados costes fijos muy difíciles de asumir por la iniciativa privada. Para este tipo de proyectos, de importantes efectos externos beneficiosos sobre la descongestión y la movilidad general, quizás a veces la fórmula de PPP no sea la más acertada, ya que ésta hace recaer el coste de la infraestructura en mayor medida sobre los usuarios (a través de las tarifas) que sobre el conjunto de la población beneficiaria (a través de los Presupuestos Generales del Estado).

\section{Filipinas y la «trampa de la renta media». La necesidad de un cambio estructural en Filipinas}

En los años cincuenta Filipinas era uno de los países más prometedores de la región asiática.

\footnotetext{
${ }^{5}$ En este sentido, el Fondo Monetario Internacional (2015) señala el peligro, quizás exagerado, de un posible crowding-out derivado de un mayor gasto público financiado con deuda frente a la alternativa de incrementar la recaudación fiscal.
}

Posteriormente fue decayendo y sólo a partir de la segunda década de este siglo comienza a verse de nuevo el verdadero potencial de este país.

Cabría plantearse si Filipinas habría caído dentro de lo que se ha dado en llamar la «trampa de la renta media» (Middle Income Trap), expresión acuñada por Gill and Kharas (2007) y usada -y a veces discutida- por organismos internacionales (Banco Mundial, 2010) que vendría a describir la situación de estancamiento del nivel de renta por habitante de algunos países «atrapados entre los países pobres de bajos salarios que dominan las industrias maduras y los países ricos innovadores que dominan las industrias de cambio tecnológico rápido» ${ }^{6}$. Esta definición resulta algo tautológica, pero en cualquier caso, y a nuestros efectos, no nos interesa tanto saber si existe o no una «trampa» como hecho estilizado, sino de saber si un país como Filipinas va camino de convertirse en un país de renta alta en un futuro no muy lejano y qué requeriría para ello.

En este sentido, Felipe et al. (2014) analizan la evolución de 124 países en el período 1950-2013 (remontándose más atrás en 72 de ellos para los que existen datos) y los clasifican en renta baja, mediabaja, media-alta y alta según unos umbrales de renta por habitante en paridad de poder adquisitivo a precios de 1990: 2.000, 7.250 y 11.750 dólares, respectivamente (de modo que un país de renta media sería aquél entre 2.000 y 11.750 dólares de renta). Para el período analizado, los autores llegan a la $\triangle$

\footnotetext{
${ }^{6}$ Gill and Kharas (2007).
} 


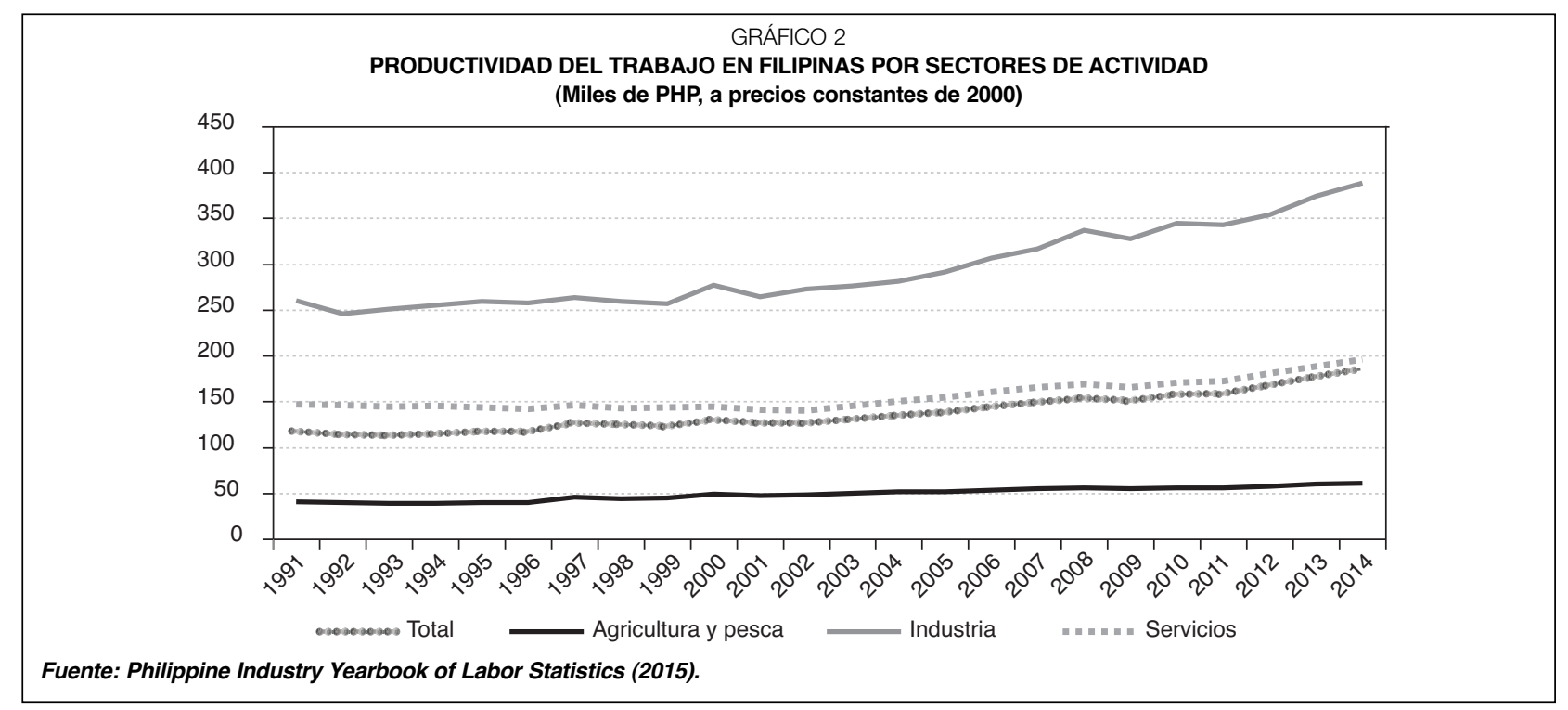

conclusión de que, salvo contadas excepciones, los países presentan una tendencia histórica alcista en su nivel de desarrollo, lo que a priori descartaría la existencia de una trampa de la renta media como hecho estilizado en la historia del desarrollo económico. No obstante, dicha tendencia histórica alcista se produce con ritmos disímiles: antes de 1950 un país tardaba de media 64 años en pasar de ser de renta media-baja a renta media-alta, mientras que después de 1950 esa media se reduce a tan sólo 28 años (siendo valores atípicos algunos países asiáticos como China, Japón, Corea del Sur, Hong-Kong o Singapur). Asimismo, comprueban que la transición de renta media-alta a renta alta (país desarrollado) es mucho más rápida, y transcurre antes de 1950 en un plazo medio de 20 años y después de 1950 en apenas 14 años (también con algunos países de Asia como valores atípicos).

En este contexto, se podría decir que Filipinas, con una renta por habitante en 2013 de 3.429 dólares en PPA, lleva 39 años como país de renta media-baja y dispondría aún de 16 años más para alcanzar el nivel de renta media-alta y estar dentro de la media histórica, siempre que mantenga un crecimiento mínimo anual de su renta por habitante del 4,8 por 100 (lo que, a una tasa media de crecimiento de la población del 2 por 100 , requeriría una tasa de crecimiento del PIB cercana al 7 por 100).

Por tanto, Filipinas se encuentra aún a tiempo, en términos históricos, para llegar a ser un país de renta alta.
La cuestión entonces es cómo asegurar un adecuado crecimiento para Filipinas que le permita convertirse en un país de renta alta, para lo cual la clave está en conseguir una transformación estructural en Filipinas que le permita convertirse en una economía industrial y de servicios moderna.

Para ello, Felipe et al. (2014) destacan la industrialización como uno de los factores relevantes para alcanzar mayores niveles de renta por habitante. El motivo es evidente: la productividad de la industria manufacturera suele ser muy superior a la productividad en los servicios (con la excepción de los servicios financieros), lo cual permite remunerar más a sus trabajadores, Filipinas es un buen ejemplo, con una tasa de productividad de la industria entre 2 y 3 veces superior a la del sector servicios no financieros.

Ahora bien, de su análisis se obtiene que el empleo industrial resulta ser mejor predictor del futuro crecimiento de la renta por habitante que el PIB industrial, de modo que históricamente ningún país que no haya alcanzado al menos un 18 por 100 de empleo en la industria ha conseguido cruzar el umbral de los 10.000 dólares de renta por habitante.

Siguiendo esta línea argumental, en el caso de Filipinas la clave está en conseguir que un mayor porcentaje del empleo se dirija al sector industrial.

Por desgracia, la tendencia no es esa. Las cifras muestran que, en el período 1973-2014, el empleo agrícola en Filipinas ha pasado de representar el 55 por 100 de la población ocupada al $\triangleright$ 


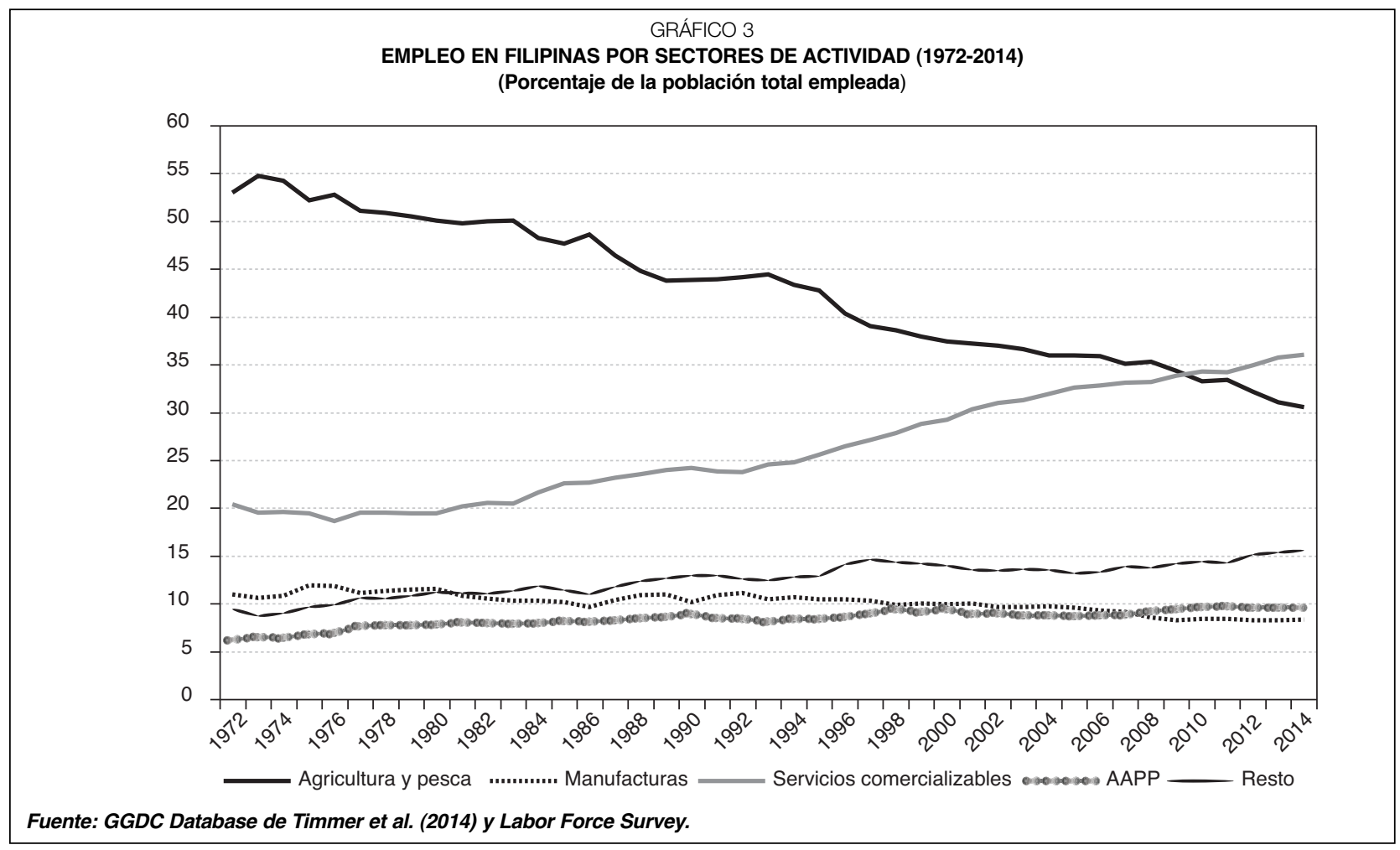

31 por 100. Por su parte, los servicios comercializables han pasado de absorber el 20 por 100 de la población ocupada al 36 por 100. Mientras, los servicios públicos y comunitarios, sociales y personales han pasado del 11 al 18 por 100 del empleo, y la industria manufacturera ha caído del 11 al 8 por 100 del empleo total.

En este proceso se ha observado una progresiva caída de la industria de los semiconductores, que en los años noventa prometía convertirse en uno de los factores de desarrollo del país. Sin embargo, el fuerte desarrollo de otros países de la zona ha impedido a Filipinas sacar partido del sector de la electrónica y potenciarlo más allá del mero ensamblaje, dejando que languidezca. Así, si en el año 2000 las exportaciones de productos electrónicos suponían un 74 por 100 de las totales, en el año 2013 apenas representaban un 20 por 100 (FMl, 2013).

Esto quiere decir que en Filipinas la población agrícola se ha desplazado masivamente al sector servicios sin pasar por el sector industrial, y al de servicios, en general, de baja productividad (comercio, BPO), donde los salarios no tienen muchas posibilidades de crecer. Al contrario que en los países desarrollados, donde la desindustrialización ha venido precedida de una industrialización previa, en países como Filipinas la desindustrialización se está produciendo sin que haya habido industrialización previa.

¿Podría ser el sector de BPO, uno de los fijados como objetivo para el Gobierno filipino, un sector estratégico de crecimiento? Es posible, pero no con la estructura actual. Considerando (a falta de datos sobre productividad) los ingresos por trabajador, este sector proporcionaba en 2013 unos ingresos anuales de 15.300 millones de dólares (equivalentes al 5,6 por 100 del PIB) y daba empleo a 850.000 personas (equivalentes al 2,2 por 100 de la población activa) (BSP, 2015). Eso quiere decir que, en media, cada empleado de un centro de BPO genera casi 18.000 dólares al año. Ahora bien, este ingreso por trabajador es muy distinto según el tipo de centro: así, los centros de voz (call centers) generan unos ingresos por trabajador de apenas 15.800 dólares al año, mientras que los centros de desarrollo de software generan 41.500 dólares al año por trabajador (lo que hace suponer una productividad mucho mayor). Por desgracia, los $D$ 


\begin{tabular}{|c|c|c|c|c|c|c|}
\hline \multicolumn{7}{|c|}{$\begin{array}{l}\text { TABLA } 5 \\
\text { INGRESOS Y EMPLEO EN EL SECTOR DE CENTROS BPO (2005-2013) }\end{array}$} \\
\hline & \multicolumn{3}{|c|}{ Ingresos (M USD) } & \multicolumn{3}{|c|}{ Empleados (miles) } \\
\hline & 2005 & 2009 & 2013 & 2005 & 2009 & 2013 \\
\hline Centros de llamadas..................................... & 936 & 4.207 & 8.394 & 96.246 & 255.765 & 530.882 \\
\hline 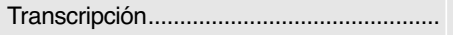 & 8 & 57 & 423 & 1.785 & 7.060 & 20.172 \\
\hline Animación & 17 & 52 & 88 & 1.864 & 3.732 & 4.206 \\
\hline Desarrollo software & 399 & 1.672 & 3.429 & 17.829 & 46.987 & 82.585 \\
\hline Otros BPO & 585 & 2.270 & 2.971 & 20.278 & 131.267 & 213.939 \\
\hline Total industria & 1.996 & 8.258 & 15.305 & 138.002 & 444.811 & 851.782 \\
\hline
\end{tabular}

centros de voz, con una demanda mucho más vulnerable a variaciones en los costes salariales debido a su menor valor añadido, suponen el 62 por 100 del empleo, frente a un 10 por 100 de los centros de desarrollo.

El sector de BPO, por tanto, sólo podrá ser un sector de futuro si consigue impulsar los centros de alto valor añadido y con una menor elasticidadprecio de la demanda.

¿En el contexto actual, cómo podría avanzar Filipinas y garantizar un crecimiento sostenido del nivel de renta por habitante?

La solución, por supuesto, no es fácil. La globalización y las tecnologías de la información y de las comunicaciones han hecho que los procesos y técnicas industriales sean ahora menos trabajo-intensivos y generen un efecto desbordamiento mucho más rápido. Por otro lado, las estructuras institucionales políticas, laborales y sindicales de muchos de los países ahora desarrollados, y que sin duda contribuyeron a los mayores salarios industriales, no son fácilmente replicables en otros países en desarrollo actuales. Finalmente, en un mundo globalizado y altamente competitivo, una gran parte de las ganancias de productividad se transforma en menores precios para garantizar la competitividad internacional. De este modo, industrializarse en el siglo XXI es quizás más sencillo en términos tecnológicos que hace un siglo, pero probablemente sea mucho menos rentable.

\section{Una estrategia adecuada de desarrollo}

Filipinas, que se caracteriza por su baja productividad en relación con otros países de su entorno, tiene muchas posibilidades de mejora. Para favorecer un cambio estructural debería actuar en varios frentes.

En primer lugar, no será fácil lograr aumentar la productividad ni la eficiencia sin un adecuado marco institucional y económico. Así, factores como la seguridad jurídica y la lucha contra la corrupción, los incentivos fiscales y no fiscales para el autoempleo, la formación profesional, los incentivos para la investigación y el desarrollo y la innovación, la simplificación de los trámites legales para iniciar un negocio, la estructura de la tierra o los efectos desbordamiento positivos de la competencia (traída en gran medida por la inversión directa extranjera) son factores que pueden resultar cruciales en el medio plazo. En este ámbito se incluye, por supuesto, la resolución política de problemas como el de Mindanao, que permitiría terminar con la dualidad del país y aprovechar el enorme potencial de esa zona.

En segundo lugar, será necesario promover una adecuada industrialización, entendida no sólo como una mera sofisticación de la industria manufacturera actual (demasiado limitada al ensamblaje de semiconductores), sino también, y quizás en mayor medida, a una modernización de la agricultura y una industrialización indirecta de la misma, favoreciendo el desarrollo de productos agrícolas más elaborados y de mayor valor añadido. Para ello es necesario favorecer el desarrollo de un sector privado moderno, donde prevalezca una cultura de emprendimiento, y que permita (con información y otros bienes públicos facilitados por las Administraciones, y en coordinación con éstas) fomentar la $\triangleright$ 
producción de bienes de consumo con una alta elasticidad-renta de la demanda y productos intermedios complejos, aprovechando las ventajas competitivas existentes ${ }^{7}$.

En tercer lugar, será necesario fomentar los servicios de mayor valor añadido. En el ámbito de la tecnología, los BPO de voz suponen una buena base de partida para favorecer los centros de desarrollo de ingeniería, software, financieros $u$ otros de valor añadido. Filipinas tiene una población angloparlante, joven y con capacidad de formación que puede garantizar la permanencia de los BPO en el país vinculándolos a factores menos volátiles que los bajos costes laborales. Asimismo, Filipinas podría favorecer el desarrollo de un sistema bancario moderno, con servicios financieros de valor añadido, para lo cual la inversión extranjera (recientemente liberalizada) será fundamental. En última instancia, son los servicios intensivos en conocimiento los que permiten en última instancia una mayor absorción de empleo y unos mayores salarios.

Finalmente, la imperiosa necesidad de unas infraestructuras mejores en los ámbitos de los transportes y las comunicaciones requiere un sector público decidido a acometer grandes inversiones con cargo a sus presupuestos, admitiendo un cierto deterioro en sus saldos a corto plazo pero que garantice un crecimiento potencial adecuado y una adecuada reducción de las desigualdades.

\section{Conclusiones}

Filipinas ha experimentado un fuerte crecimiento en los últimos años hasta convertirse en un país con sólidos fundamentos macroeconómicos, al menos desde el punto de vista de la sostenibilidad financiera. Sin embargo, persisten debilidades estructurales importantes como un elevado subempleo

\footnotetext{
7 Evitando, lógicamente, la quimera de intentar ser competitivo en productos en absoluto relacionados con las ventajas existentes en el país, tanto en términos de materias primas como de habilidades empresariales preexistentes.
}

y unas deficientes infraestructuras que impiden que el crecimiento derive en una mejora de las condiciones de vida para sus ciudadanos y en un trampolín para mayores niveles de renta por habitante y de desarrollo.

Hasta el momento el sector público ha concentrado sus esfuerzos en facilitar la inversión privada local, desatendiendo la inversión extranjera y, sobre todo, la inversión pública, crucial para desarrollar las débiles infraestructuras filipinas y aumentar el crecimiento potencial. Precisamente la solidez financiera de Filipinas da mucho margen para potenciar ambiciosos programas de inversión pública sin comprometer los equilibrios esenciales, y que permitan alcanzar niveles de stock de capital público similares a los de otros países de su entorno.

Filipinas no ha caído en la trampa de la renta media: tiene aún tiempo para, en términos históricos, convertirse en un país de renta media-alta y luego alta si acomete las reformas necesarias y provee un marco adecuado para el crecimiento. Favoreciendo una modernización de la agricultura, una industrialización inteligente, una potenciación de los servicios de valor añadido (sin conformarse con los hasta el momento poco rentables BPO) y unas infraestructuras suficientes, estará en condiciones de acometer la trasformación estructural necesaria para, esta vez sí, responder a las expectativas de su enorme potencial.

\section{Bibliografía}

[1] BANGKO SENTRAL NG PILIPINAS (2015). 2013 Survey of the Information Technology-Business Processing Outsourcing (IT-BPO) Services

[2] BHATTACHARYAY, B. (2010). «Estimating Demand for Infrastructure in Energy, Transport, Telecommunications, Water and Sanitation in Asia and the Pacific: 2010-2020». ADBI Working Paper Series, $\mathrm{n}^{\circ}$. 248, Septiembre de 2010. Manila.

[3] CALDERÓN, C. y SERVÉN, L. (2004). «The Effects of Infrastructure Development on Growth and Income Distribution». Policy Research Working Paper, $\mathrm{n}^{\circ}$ 3400. World Bank, Washington, D.C. 
[4] FELIPE, J.; MEHTA, A. y RHEE, C. (2014). «Manufacturing Matters... But It's the Jobs That Counts». ADB Economic Working Paper Series, $n^{\circ}$ 420. Manila.

[5] FONDO MONETARIO INTERNACIONAL (2013). Philippines Country Report, $n^{\circ}$ 13/102.

[6] FONDO MONETARIO INTERNACIONAL (2015). Philippines Country Report, $n^{\circ}$ 15/246.

[7] GILL, I. y KHARAS, H. et al (2007). An East Asian Renaissance: Ideas for Economic Growth. World Bank: Washington, DC.

[8] SENEVIRATNE, D. y SUN, Y. (2013). «Infrastructure and Income Distribution in ASEAN-5:
What are the Links?». IMF Working paper WP713/41.

[9] TIMMER, M.P.; DE VRIES, G.J. y DE VRIES, K. (2014). «Patterns of Structural Change in Developing Countries». GGDC research memorandum, $\mathrm{n}^{\circ} 149$.

[10] WORLD BANK (2005). Philippines: Meeting Infrastructure Challenges.

[11] WORLD BANK (2010). «Research for Development: A World Bank Perspective on Future Directions for Research». World Bank Policy Research Working Paper, $\mathrm{n}^{\circ}$. 5437, Washington, DC.

[12] WORLD BANK (2012). Infrastructure Strategy Update FY2012-2015: Transformation Through Infrastructure. 
